Estudios Románicos, Volumen 28, 2019, pp. 247-258

ISSN: 0210-491

eISSN: 1989-614X

DOI: https://doi.org/10.6018/ER/375041

\title{
POÉTICA CUÁNTICA: FICCIÓN DEL COSMOS DE MIRCEA CĂRTĂRESCU
} (Quantum Poetic: Mircea Cărtărescu's cosmos fiction)

\author{
Claudia García-Minguillán* \\ Universidad de Salamanca
}

\begin{abstract}
This article aims to propose a theoretical framework, as a poetic, of the brief narrative of the Romanian author Mircea Cărtărescu. Several links between the stories that make up Nostalgia point to an intertextuality placed by the author in strategic points of the narrative, which generate a sense of union between the different stories. These strategic points of fiction begin with the story of a Russian roulette player. The mathematical principles set out there formulate the theory of possible worlds in a fictional key. We will analyze, therefore, the origins of this narrative technique in the currents of quantum physics.
\end{abstract}

Keywords: Cărtărescu; Quantum Physics; Fiction; Roumanian Literature.

Resumen: Este artículo propone un marco teórico, a modo de poética, de la narrativa breve del autor rumano Mircea Cărtărescu. Numerosos nexos entre los relatos que componen Nostalgia apuntan a una intertextualidad situada por el autor en puntos estratégicos de la obra, los cuales generan una sensación de unión entre las distintas historias. Estos puntos estratégicos de la ficción tienen inicio con el relato de un jugador de ruleta rusa. Los principios matemáticos ahí planteados, formulan, en clave de ficción, la teoría de los mundos posibles. Analizaremos, por tanto, los orígenes de esta técnica narratológica en las corrientes más actuales de la física cuántica.

Palabras clave: Cărtărescu; Física Cuántica; Ficción; Literatura Rumana ${ }^{1}$.

\footnotetext{
*Dirección para correspondencia: Claudia García-Minguillán. Área de Teoría de la Literatura y Literatura Comparada. Departamento de Lengua Española. Facultad de Filología. Universidad de Salamanca. Plaza de Anaya s/n, 37008, Salamanca. (cgmt@usal.es)

1 Quede reflejado mi profundo agradecimiento a la Prof. Dr. Luminiţa Marcu por la formación académica recibida y por su generosa guía, sin las cuales este trabajo, surgido en los primeros años universitarios, no habría visto la luz. Possunt, quia posse uidentur (Virgilio, En. V, 231).
} 
Todo principio de suposición comienza en la hipótesis, y esta, a su vez, comparte origen con el campo de la ficción. Por lo tanto, independientemente de la materia en la que nos encontremos, estudios de literatura, o de física cuántica, ambos parten del mismo elemento ficcional. Esta tesis, defendida en la obra canónica Poética de la ficción (1993) del profesor Pozuelo Yvancos, soluciona el debate de las analogías existentes entre campos en apariencia tan distanciados como son la física y la literatura.

El propósito de este artículo se aleja de dar sentido ontológico a referencias poéticas adornadas con una terminología científica y aún menos pretende abordar el complejo debate de la epistemocrítica contemporánea. Sí pretendemos, por el contrario, analizar la técnica puramente narratológica fundamentada en una analogía de una de las teorías más conocidas en la actualidad y -de acuerdo a como indica Vicente Luis Mora (2016)menos entendidas, como son los principios de física cuántica y, en concreto, la teoría de la relatividad de Einstein.

El empleo de conceptos propios de las nuevas teorías que relacionan el tiempo con el espacio no es una novedad dentro de los estudios filológicos. Ya Bajtín en Teoría y Estética de la novela (1989), recurría al concepto matemático de 'cronotopo' para explicar la relación inescindible entre el tiempo y el espacio en la novela. Y antes de él, Brunetière (1890) explicaba los géneros literarios históricos y sus interferencias en clave de principios de genética. Tampoco es una novedad aplicar elementos de física a la literatura, ya se dio el caso, entre muchos otros, en Ryan (1985) con su propuesta de la matriz de los estados narrativos que sostiene la teoría de los mundos posibles. Las relaciones entre estos últimos elementos, física y literatura, se pueden estudiar desde la analogía entre la creación de espacios narrativos y el surgimiento de nuevos mundos. De dicha técnica nace, quizás inconscientemente, la narrativa breve de Mircea Cărtărescu, iniciada con el cuento El Ruletista. Este primer relato cuenta una historia en la que el azar matemático de la ruleta rusa marca la vida de un hombre. De estos principios del multiverso nacientes de menciones puramente matemáticas y cuánticas, se componen el resto de los relatos de la antología Nostalgia. Las interferencias entre las distintas historias favorecen una interpretación en la que el principio cuántico sustituye a su analogía más conocida en teoría literaria como mundos posibles. Estas historias proponen un 'horizonte cósmico' de la ficción literaria del autor, de la que proponemos un análisis en el marco de la geometría del cosmos ficcional.

Como autor ya asentado en la valoración del público, su obra ha sido progresivamente reconocida por la crítica literaria, de la que ha recibido sendos premios internacionales, los últimos, Premio Thomas Mann de Literatura y Formentor de las Letras, 2018, además de ser candidato al nobel. Su obra, esencialmente narrativa, mantiene un componente lírico con el que dio inicio a su carrera literaria. Visul (1989) y Levantul (1990) representan el estilo de su autor, siendo de las pocas obras de juventud traducidas al español, como es el caso de Nostalgia (Impedimenta, 2012) y El Levante (Impedimenta, 2015), aunque este último es una adaptación lingüística realizada por el autor del original Levantul para que pudiera ser traducido. Un interesante estudio de Alexandrescu (2016) desvela las fases de traducción y adaptación de la obra.

Con todo, la literatura científica no colma todavía el gran campo de estudio que encontramos en la obra de su autor y, por extensión, en toda la literatura rumana. Aún 
así, contamos con los valiosos estudios de Alexandrescu (2016; 2017) y Iacob (2017a; 2017b) y Posada (2018) donde se analiza la presencia del autor en la actualidad española. Algunas investigaciones se centran en estudios temáticos de la obra, como son los casos de Ciobanu (2002), Cernat (2007), Muñoz (2011), Dimitru (2012; 2014), Buda (2014), y distintas publicaciones de Diz (2015a; 2015b), fruto de su labor doctoral centrada en la figura de este escritor. Esta ha formado parte a su vez de eventos divulgativos como el congreso sobre la figura del escritor rumano celebrado en la Universidad Autónoma de Barcelona en mayo del pasado año, evento que sirvió como prefacio a la presencia de Cărtărescu en la Feria del Libro de Madrid 2018, con Rumanía en calidad de país invitado. En último lugar, cabe mencionar un estudio recientemente publicado por Pujante (2019). El conjunto de estos trabajos ha favorecido el desarrollo de este artículo que formula una propuesta de la poética del autor.

\section{Describir la 'parábola viva': la poética cuántica del Ruletista}

Cerca del cenáculo literario de la ciudad de Bucarest, se publicaba la resonante vida de un jugador de ruleta rusa, narrada por Mircea Cărtărescu. A través del murmullo "A căzut Tirania!” de la Revolución de 1989, meses previos a Diciembre, Visul (El Sueño) se convertía en la primera gran publicación de su autor. El volumen, gestado en el mismo "grembo materno" de la epopeya nacional Levantul, está compuesto por cinco narraciones. Entre ellas, una sufrió la censura ${ }^{2}$ por su desgarrado realismo y ferocidad prosística con la que el autor nos presenta a un hombre. El Ruletista es la historia de un personaje de ficción literaria de la que un narrador es testigo. El relato, "proyecto de inmortalidad" de su autor, comienza con un monólogo indirecto del escritor-testigo, donde plantea la delgada línea entre la verosimilitud literaria, el testimonio y la ficción. El autor, en su faceta ficcional de narrador a la vez que testigo, reflexiona: "Qué extraño: la mayoría de los personajes que pueblan mis libros son inventados pero todo el mundo los ha tomado por copias de la realidad" (Cărtărescu 2010b: 19). Con toda probabilidad, la dificultad para distinguir entre lo real y lo ficticio es provocada por la tensión y la oquedad prosística que genera una indirecta prosa tremendamente flaubertiana ${ }^{3}$, además de contar la historia de un hombre corriente.

En el espacio nocturno de la ciudad, el narrador-testigo dirige sus pasos hacia una ficción subterránea, un sótano donde se llevan a cabo acciones al margen de la ley, entre ellas la práctica de la ruleta rusa. Días se lleva gestando la mitología entorno al ruletista, del que afirman que puede violar las leyes de la física. Sus reiterados intentos por encontrar la muerte le deparan gloriosas supervivencias, nuevas vidas para "vislumbrar al infinito Dios matemático y luchar cuerpo a cuerpo con él” (Cărtărescu 2010b: 21). Pues la síntesis del suceso es la continua presencia del ruletista en el cenáculo mórbido de

2 Marian de Ochoa, traductora de la obra de este autor, lo recuerda en su introducción al Ruletista.

3 La ambigüedad que genera un gran dominio del estilo indirecto fue conquista de Flaubert, como diversos críticos han identificado como Mario Vargas Llosa (1978), o taxonomizado como Marguerite Lips (1926). En el contexto cultural de Rumanía, Schneider (2016) ha estudiado el discurso de 'auto-representación' en su narrativa y la influencia posmodernista. 
violencia que es ese espacio al margen de lo permitido en la ciudad ${ }^{4}$. La tensión ante la supervisión del revólver, cuando procede a contar las balas, alcanza el valor de un ritual de preparación en el que el momento queda embalsamado en un tiempo novelesco dilatado y ralentizado. El protagonista realiza numerosos intentos en la ruleta, y promueve la presencia de asistentes voraces por ser testigos de su muerte cada vez más inminente. El ruletista reduce sus posibilidades de supervivencia y, en su último intento, el revólver cargado con las seis balas dictamina la sentencia de lo que todos esperan ${ }^{5}$. Las apuestas acompañadas de una pletórica euforia descomponen el espacio entre los asistentes cuando, ante un silencio místico, un terremoto altera las normas no dictaminadas del azar y, ante el pavor y el pánico de presenciar un evento sobrenatural, el ruletista, tumbado en el suelo, en un estado catártico de apoplejía, sobrevive, por última vez, a la ruleta.

Este relato es para Mircea Cărtărescu la formulación técnica de su poética cuántica. El juego de la ruleta rusa es una práctica lúdica de azar, en la que varios sujetos sortean la muerte por arma de fuego, animados por un sistema de apuestas ${ }^{6}$. Más allá, la adicción generada por el juego se vivifica por la intensidad con la que se viven los momentos previos al disparo. Esta concentración es el proceso en el que el universo matemático comienza su cálculo y, con el resultado, sea positivo o negativo, nuevos mundos aparecen.

En una ficción dentro de la ficción, el narrador cuestiona: “CCómo voy a describir una parábola viva?". El ruletista es la "parábola viva" pues, en sentido matemático, supone una curva formada por dos líneas simétricas respecto un eje referencial, del que todos los puntos se encuentran alejados a la misma distancia. Es decir, el mismo origen, con dos destinos distintos. Más allá de este sentido metafórico, las referencias matemáticas en el relato son técnicas, lo que indica una consciente formulación de la teoría de los universos múltiples de Hugh Everett. La teoría de la relatividad general de Einstein, precursora de estas hipótesis cuánticas, consiguió afirmar que el universo está en expansión y que, por tanto, es infinito. Infinito como el Ruletista, que abarca todo el universo en su persona hasta abordar a los asistentes de la ficción: "Miles de millones de galaxias, campos imperceptibles, en fin, este universo que rodea mi cabeza como un aura no podría existir si yo no tuviera que conocerlo en su totalidad, poseerlo, ser él" (Cărtărescu 2010b: 54).

Esta poética de lo iterable propone un símil de la experiencia cuántica, conocida coloquialmente como "suicidio cuántico", a la manera del famoso experimento del gato de Schrödinger. Siempre en el marco teórico el suicidio cuántico fue formulado como experimento mental por Tegmark (1999). El experimento consiste en dirigir la narración desde el lado de la "víctima", en este caso, el ruletista. Por cada disparo, el universo se divide en la posibilidad "bífida" de muerte o vida, por lo tanto, el ruletista siempre estará vivo y muerto en un número infinito de universos, esta es la denominada 'inmortalidad cuántica'.

\footnotetext{
$4 \quad$ "La ruleta posee, en principio, la simplicidad geométrica y la fuerza de una telaraña: un ruletista, un patrón y unos accionistas son los personajes del drama" (Cărtărescu 2010b: 32)

5 “Porque el Ruletista había anunciado unas semanas antes que en la próxima ruleta cargaría el revólver con las seis balas! Entre la evolución de un cartucho a cinco - por muy inverosímil que fuera también esta- y la locura de ahora se abría el abismo entre una posibilildad o ninguna." (Cărtărescu 2010b: 51)

6 "El ruletista tiene cinco posibilidades de entre seis de escapar con vida. Recibe habitualmente el diez por ciento de la ganancia del patrón" (Cărtărescu 2010b: 33)
} 
Con este brevísimo y metafórico repaso de las posibilidades hipotéticas que ofrece la teoría de los universos cuánticos, podemos aplicar la teoría y reconocer una verdadera poética, una verdadera norma compositiva que atraviesa la obra Nostalgia y Lulu, ambas pertenecientes al proyecto Visul, y que tiene origen en el relato del Ruletista. Con el objetivo de responder a la cuestión formulada por Ronen (1994: 10): "To explore the unique nature of fiction we should first ask how far the analogy between possible and fictional worlds has brought us in this respect", analizaremos el alcance de esta analogía en el proyecto de ficción de Mircea Cărtărescu con el fin de confirmar si bien es una intuición poética o una norma compositiva.

\section{Los mundos (cuánticos) posibles de la ficción literaria}

La antología de relatos Nostalgia sucede al relato del Ruletista. Este conjunto de la narrativa breve de Mircea Cărtărescu, es una composición estética inspirada y alimentada en la obra cinematográfica homónima de 1983, del cineasta Andréi Tarkovski. En esta, un poeta, Andréi Gorchakov, viaja a Italia para documentar la vida de un músico ruso del siglo XVIII. La búsqueda de la pista del músico convive con la búsqueda de Andréi en sí mismo. La experiencia mística y la poética se mezclan en un intento por comprender un sentido vital. El espacio se reparte entre el mundo terrenal y espacios místicos, no-reales, o incluso soñados. Este doble terreno de la ficción surge en Cărtărescu y en toda su generación con el movimiento conocido como 'onirismo'. Frente a Nostalghia de Tarkovski', Nostalgia de Cărtărescu se compone de 3 partes: el Ruletista a modo de prólogo, el cuerpo de la obra compuesto por los relatos El Mendébil, Los gemelos, y REM, y El arquitecto, a modo de epílogo. Tras la historia del ruletista, lo sucesivo es una extensión del principio de esta poética cuántica, que comienza con la historia de 'Mendébil'. Esta historia localizada en la infancia más remota y onírica del autor, cuenta cómo un grupo de niños juega con la fantasía en las últimas largas tardes de verano. El niño apodado con el título del relato gana la atención del grupo por su extravagante discurso y costumbres. Entre ellos, surge una 'teoría' sobre un marionetista que, como elemento proto-existente, existe dentro de nosotros. Esta excentricidad engatusa al grupo de jóvenes y se entusiasman con la idea de ser parte de un microcosmos de marionetistas en múltiples dimensiones:

[...] en mi marionetista existe otra marioneta, que está en el interior de su cráneo y que es idéntica a mí, y en su interior otra más pequeña y así hasta el infinito. Y mi marioneta maneja otra marioneta, mucho más grande, en cuyo cráneo vive, y que maneja a su vez otra marioneta, y así hasta el infinito. Su mundo es igual al nuestro. (Cărtărescu 2012: 63)

7 Observamos elementos que animan un estudio de la obra de Cărtărescu en clave de la cinematografía, especialmente, de Tarkovski, pues las relaciones se revelan progresivamente obvias. En Lulu (Impedimenta (Cărtărescu 2011), Víctor, el protagonista, es un adolescente de gran sensibilidad lírica, cuyo aspecto débil y un tanto afeminado, provocan una dualidad entre ambos sexos generada, en parte, por una hermana gemela fallecida durante la infancia. El protagonista del primer film de Lars von Trier "Orchidégartneren" (1977), muy influido por el cineasta ruso, se llama Víctor, y presenta esta misma estética. 
La voz del autor atraviesa el discurso indirecto libre para personificarse y aparecer como un personaje más dentro de la diégesis. Identificamos incluso un desdoblamiento del carácter, pues muchas intervenciones del autor transmiten el sufrimiento de revivir esas historias de la mano de la lectura, por lo que, a estas alturas, Cărtărescu ya ha sido el ruletista y el mendébil. Esta vivencia del autor revela la técnica de los mundos posibles como inevitable dentro de su poética. Pues no es una mera creación de personajes que comparten elementos del bagaje de un autor, sino que son los mismos mundos los que aparecen y desaparecen de manera intermitente:

El mundo de alrededor es el mismo para mí y para él. Y a mi marionetista y a mi marioneta lo rodean un Luta y un Lumpa y un Mimi y vosotros, todos los demás, y los que son igual que vosotros. El tapón de cerveza del suelo existe también en el mundo muy, muy, pequeño de mi marionetista, y en el mundo muy, muy grande de mi marioneta. Porque todo es igual. (Cărtărescu 2012: 63)

Aquellas referencias a lo infinito, a la estructura del multiverso que se expande progresivamente, ya aportan unas bases sólidas a este análisis de la narratología del autor. Cărtărescu deja, como un pastor la siembra, portales para acceder a estos mundos. Como en Proust, lo sensorial es un factor elemental para el acceso a los mundos cuánticos y uno de ellos es el primer sorbo de Nes, la marca de café soluble de época soviética, que conectaba la psique del autor con la creación poética. De hecho, su primer contacto con la bebida fue por su tía Vasilica, uno de los personajes de Cegador. Más allá, en la misma ficción, encontramos 'portales' de comunicación entre las mismas obras. Presenciamos un ejemplo en Mendébil:

Cuando estuvo bien cerca, vi su ojo almendrado, enorme, que crecía como dentro de una lupa y que de repente me abarcó por todas partes. Me tapé la cara con un sentimiento terrible de vergüenza y de placer. Cuando volví a mirar, observé que en las paredes del frasco -que lanzaban destellos demenciales- habían aparecido los contornos delicados de una puerta. (Cărtărescu 2012: 44-45)

La relación del "ojo almendrado" y la "puerta" indican una salida dirigida por un referente, un camino hacia otra diégesis ${ }^{8}$. Esto se confirma pues, uno de los últimos trabajos publicados por Cărtărescu es la obra Ochiul caprui al dragostei noastre (El ojo castaño de nuestro amor, 2016, Impedimenta).

8 No es lugar este artículo para abarcar esta técnica, pero, a modo de introducción para otro trabajo, mencionaremos las múltiples referencias a aquello deslumbrante o reluciente que nubla la vista con su brillo. En Mendébil encontramos "iluminada cegadoramente" (Cărtărescu 2012: 48), "me escuecen los ojos de tanto oro y tantos destellos" (Cărtărescu 2012: 70) o en REM "Parecía la explosión extática de un cosmos, un apocalipsis y un génesis mezclados. Todo me arrastraba hacia la luz que estaba más allá de la luz.” (Cărtărescu 2012: 279). En El ojo castaño de nuestro amor, "las casitas cegadoramente blancas" (Cărtărescu 2016: 19), "recuperando espacios de su infancia en Bucarest $[$...]todo estalló en mi cerebro en un flujo de luz cegadora" (Cărtărescu, 2016: 44). Todos ellos son elementos que dirigen la lectura hacia otra obra recientemente publicada, El ala izquierda. Cegador, I (2018, Impedimenta) o, a una menos conocida, Cegador (Cărtărescu 2010a). 
El relato de Los gemelos comienza con una escena de un hombre afeitándose frente a un espejo. Una mirada a la cuchilla genera un desprendimiento emocional que provoca al personaje romper en lágrimas. De la cuchilla, describe: "En ella ponía 'London Bridge' y parecía vivir una vida propia y muy intensa. Por un impulso incomprensible, besó la cuchilla, luego se la acercó al rostro y de nuevo se le llenaron los ojos de lágrimas" (Cărtărescu 2012: 83). A continuación, describe la habitación en la que se encuentra con un filtro oscilante entre la realidad y la no realidad, para afirmar, al asomarse a la ventana, un universo paralelo para el cual, las hojas de la cuchilla, son el portal de entrada: "Si hubieras abierto una de las tres grandes hojas transparentes y hubieras sacado la cabeza por la ventana, habrías distinguido, veinte metros más abajo, sumergida en una luz roja-anaranjada, la avenida Ștefan cel Mare [...]" (Cărtărescu 2012: 84). En esta traslación el narrador se sitúa en una habitación donde el personaje, descrito como si presenciásemos un ritual, se trasviste de mujer. Primero elige la ropa, reduce el vello de su piel, luego maquilla su cara y la engalana con joyas y, progresivamente, el personaje se convierte en mujer. La referencia al signo "géminis" sostiene uno de los elementos estructurales de la literatura de este autor, el del doble, el gemelo -el mismo título de este relato9-. La escena del personaje primero hombre, luego mujer, es interrumpida con la intervención del narrador, al confesar no poder seguir describiendo esta situación. Comienza de nuevo otra historia, la de un joven adolescente huraño, con ansias de ser poeta, que conoce en el instituto a Gina, surgida justo tras esa interrupción. Gina, joven que duerme con los ojos abiertos -nueva referencia a un personaje de otra diégesis, Lulu (Impedimenta, 2011)- representa todo aquello inalcanzable en la adolescencia. Ante esta traumática verdad, el joven protagonista persigue lo 'supra humano' al renunciar a Gina y dedicarse a la experiencia poética: "Yo me sentía universal, dispuesto a convertirme yo mismo en el cosmos entero" (Cărtărescu 2012: 121).

En el último relato del cuerpo de Nostalgia, REM, el autor escribe sentado en una habitación, en la que entra una mujer: "La miro con atención para poder describírosla" y prosigue con la descripción, ajeno a su propia presencia física en la habitación (Cărtărescu 2012: 200). Añade: "Se levanta y revuelve en un armario minúsculo que curioseo ahora también yo". Cărtărescu, discípulo de Kafka, establece su presencia en la diégesis en la metamorfosis de un insecto: "Doy vueltas por la estancia cada vez más agitado. Mis patas, mis garras, mi vientre transparente ocupan toda la habitación, que resplandece cada vez más en el ocaso invernal” (Cărtărescu 2012: 201). En la misma secuencia, amplía su transformación: "Me resulta poco interesante y además tengo prisa, así que abandono el apartamento, salgo por la puerta del bloque y me arrastro, horrendo, con mis patas peludas que ocupan toda la acera, por las callejuelas encharcadas, oscuras y nevadas en torno a su casa." (Cărtărescu 2012: 202). Acto seguido, el narrador pasa de ser una especie de insecto a una bacteria que alcanza, en un medio de transporte, a "hacerme un hueco bajo su piel, a deslizarme por sus

9 En El Arquitecto, un matrimonio cumple el sueño de su vida, adquirir un automóvil Dacia. En una ocasión, mientras experimentan el confort del coche, el autor los describe como dos gemelos: "También Elena le acompañaba algunas veces y allí permanecían ambos hechizados, una hora entera, como dos gemelos en el vientre de su madre.” (Cărtărescu 2012: 349). 
capilares, a nadar en su sangre a través de sus arterias cada vez más gruesas", a ser el hombre al que la mujer de la habitación espera. En este instante el narrador es una especie de bacteria y llega a introducirse en el sistema circulatorio de uno de los personajes. Esta tendencia a lo pequeño, a lo micro, nos dirige a lo cuántico. La conexión con otros universos narrativos se produce al mencionar al personaje de Gina de "Los Gemelos", citando en cursiva su propio texto: "Una vez tuve una chica o, mejor dicho, fue ella la que me tuvo a mí. Me enseñó su habitación: ¿a que es bonita? Es madera de Noruega..." (Cărtărescu 2012: 204).

Las interrupciones o paréntesis que normalmente indican una analepsis en la propia obra del autor, concebida en ocasiones como solo una, permiten cambios de modalidad del narrador. En esta ocasión, el narrador-testigo se introduce a sí mismo en otra capa de la diégesis, para contar la historia en primera persona: "Llamo y me abres tú $\mathrm{y}$, como siempre, me dejas boquiabierto porque ansío, con un cierto embarazo, ver tu figura [...]". Antes era un insecto que se introduce en los personajes, ahora adquiere su punto de vista, su modalidad, su personalidad, su personaje y luego se desembarazada para observar y narrar la situación desde otro punto de vista. La narración ahora gira entorno a las historias que se cuentan mutuamente los amantes. Destaca, entre ellas, la historia de Bloody Mary, donde hay, a través de un objeto, una conexión con otro universo diégetico, en esta ocasión, a la obra El Levante ${ }^{10}$. Otra interrupción en la historia de REM introduce la figura de Cărtărescu. El narrador persuade al lector para que realice como primera lectura la del Ruletista:

Él escribirá, por ejemplo, dentro de dos años (desvelo esto solo para que os hagáis una idea de sus posibilidades como novelista principiante) la primera historia de este volumen, El Ruletista. Si, siguiendo una buena costumbre de lector, habéis empezado el libro al revés, leed ahora mismo El Ruletista. Es lo mejor que podéis hacer en este paréntesis en el que ellos se aman. (Cărtărescu 2012: 216)

Las menciones a otros niveles diegéticos del proyecto Nostalgia a través de la intertextualidad y las referencias indirectas a otros personajes o espacios, ya apuntan a la poética que intentamos identificar. Por ejemplo, una referencia indirecta al personaje del Ruletista, donde cuenta la historia de una familia y un padre. De él añade: "Mamá, la pobre, salía solo a las compras, y papá iba solo a su misterioso trabajo, de donde nos llegaba el dinero." (Cărtărescu 2012: 220). Sin embargo, la mención directa al Ruletista confirma la intención de que sea este relato el que marque el inicio de la lectura porque es ahí donde da comienzo la poética cuántica del autor. Las distintas celebraciones de la ruleta generan la supervivencia del ruletista en otros mundos posibles. El narrador, al trasladar su persona a la del protagonista, participa de todos esos mundos convirtiéndose él mismo en la "parábola viva", en Mendébil, en los dos gemelos de forma simul-

10 "Mary había colgado, en todas las paredes, algunas citas en griego, copiadas quién sabe de dónde, relacionadas todas ellas con el mar, con el agua: Thalassa! Thalassa!, Panta rhei y otras maravillas". Este es un breve ejemplo de las conexiones en la obra del autor, aspecto que Buda (2012) identifica en Levantul por los términos de 'virtualidad' e 'hipertexto'. 
tánea y en la mujer y en el amante de la historia de REM. Es su infancia y adolescencia la que describe, son sus anhelos por ser poeta, es su frustración por el azar de la ruleta que le depara vidas en las que encuentra siempre un conflicto. Finalizada la puesta en práctica de la poética cuántica, el epílogo allanará el camino hacia su conversión hacia la inmortalidad.

\section{3. 'El Arquitecto' y la poética del borde de la vida}

El epílogo a Nostalgia es la historia de un arquitecto, Emil Popescu, cuya obsesión es la de componer distintas melodías con un teclado instalado en su nuevo automóvil Dacia. Ante la desesperación de su mujer y la incredulidad de sus vecinos, consigue hazañas musicales como la de recomponer el himno órfico, pieza única en la historia musical. Su obstinación le permite alcanzar el dominio universal del lenguaje musical, produciéndose una verdadera simbiosis entre su persona y el automóvil, al trasladar su capacidad comunicativa a la emisión sonora de la máquina:

Todo estaba allí, en un revoltijo de texto y pentagramas torcidos que marcaban las inverosímiles explosiones del espíritu por las que Emil Popescu pasaba de una etapa a otra, de una mentalidad a otra, de unas convenciones a otras, repitiendo, redescubriendo paso a paso la historia misma de la música. (Cărtărescu 2012: 363)

El arquitecto se convierte en objeto de estudio para un profesor de música. Ante el intento de entablar comunicación con él, el profesor advierte que la única posibilidad de conseguirlo es estudiando sus composiciones. Tras pasar tiempo dentro del Dacia, se convierte en un gran especialista de su obra que progresivamente adquiere fama mundial. En consecuencia, el profesor acompaña al arquitecto como especialista de una música a la que el mundo ha generado una adicción. Una parte de la fama del pintoresco compositor recae en el profesor. Esto, y su unión con la mujer de Popescu -un tanto desatendida por la música- provoca que su vida carezca de sentido sin la presencia del arquitecto.

Pasan los años, y en una ocasión, el profesor advierte cómo Elena, su mujer, se recrea escuchando la música del Arquitecto, que cada vez adquiere una honda atrayente e indestructible, de la que no se puede huir. El profesor, ante la desesperación de perder a su mujer y no poder desvincular su vida de la del arquitecto, adquiere un hacha y mutila una de sus extremidades. En ese momento, un acto grotesco comienza. El músico ya no tiene apariencia humana, su cuerpo se ha dilatado hasta ocupar todo el espacio del interior de la carrocería del Dacia y, ante el terror del profesor, la extremidad mutilada sigue tocando la música que resuena con mayor violencia. Ante la obsesión del mundo con la música del arquitecto, la necesidad de acabar con él se convierte en un objetivo común. Tras varios intentos de acabar con la mórbida e inhumana figura, de reconquistar el silencio del que tan fácilmente se habían desprendido, intentan acabar con la vida del Arquitecto. No lo consiguen y, como reacción, la música crece y se expande, alcanza el universo: 
Cuando alcanzó el centro, sus brazos retorcidos en espiral ocuparon todo el espacio de la antigua galaxia. La materia de sus brazos y de su cuerpo, que durante la migración había llegado a un enrarecimiento extremo, se condensó a lo largo de un periodo de tiempo inconmensurable, perdió su continuidad y se concentró en las partículas estelares que se habían encendido de repente en el universo vacío y oscuro. Una joven galaxia giraba ahora, latiendo y palpitando, en el lugar de la antigua. (Cărtărescu 2012: 375)

La inmortalidad del arquitecto, su extensión hacia todo el universo, a la vez que su fantasmagórica figura, da fin a la "parábola viva" que no es otra cosa que la figura del poeta. El creador se traslada, cómodo en el denominado por Ryan (1985) "narrative move", por los múltiples universos que han surgido tras cada disparo de la ruleta en la matriz de los universos posibles. En el mundo de la física cuántica, el poeta otorga una nueva función a Prometeo, la de alterar el resultado de los números, vencer al 'Dios matemático', porque, como dice el narrador del Ruletista, "hay un lugar en el mundo donde lo imposible es posible, se trata de la ficción, es decir, la literatura. Allí las leyes del cálculo de probabilidades pueden ser infringidas, allí puede aparecer un hombre más poderoso que el azar".

Este análisis transversal de la narrativa breve de Cărtărescu ha propuesto una interpretación de la narratología del autor, la cual, defendemos, se fundamenta en los principios cuánticos de la teoría del multiverso. Y no es una simple recreación de los mundos posibles, sino una consciente poética a la que da inicio El Ruletista. En este sentido, se descarta el empleo de los conceptos de intertextualidad o hipertexto por allanar la interpretación hacia un mero intercambio de referencias, y no atender a las claras alusiones a los principios cuánticos.

Más allá, su preceptiva presenta un claro asentamiento en términos científicos próximos también a la biología. El solenoide, en sentido laxo, es la espiral de la estructura del $\mathrm{ADN}$, pero es también el título de la última obra de Cărtărescu editada por Impedimenta (2018). Además, su obra se encuentra plagada de figuras "artropódicas" y elementos anatómicos, confesando el mismo autor que compone sus obras acompañado de grandes manuales de zoología y botánica.

Queda por resolver si esta poética se corresponde también con el resto de la obra del autor. Hemos mencionado brevemente la presencia de puentes de unión entre las distintas diégesis al margen de Nostalgia y Lulu. Dejamos para futuras investigaciones la interpretación del relato 'La chica del borde de la vida', localizada en la obra El ojo castaño de nuestro amor.

\section{BIBLIOGRAFÍA}

ALEXANDRESCU, Ioana (2016): "Levantul in spaniolă", Journal of Romanian Literary Studies, 9, 263-266.

(2017): "Mircea Cărtărescu en español: estado de la cuestión", Enthynema, 19, 97-108. 
BAJTIN, Mihail (1989): Teoría y estética de la novela. Madrid: Taurus.

BRUNETIÈRE, Ferdinand (1890): Nouvelles questions de critique. Paris: Ancienne Maison Michel Lévy Frères.

BUDA, Dimitru (2012): "Virtuality and Hypertext in Mircea Cărtărescu's Levantul", Studia Universitatis Petru Maior. Philologia, 12: 77-85.

(2014): "Elogiul Nostalgiei. The Eulogy of Nostalgia", Studia Universitatis Petru Maior. Philologia, 17: 52-57.

CĂRTĂRESCU, Mircea (2010a): Cegador. Madrid: Funambulista.

(2010b): El Ruletista. Madrid: Impedimenta.

(2011): Lulu. Madrid: Impedimenta.

(2012): Nostalgia. Madrid: Impedimenta.

(2016): El ojo castaño de nuestro amor. Madrid: Impedimenta.

CERNAT, Paul (2007): "Apocalipsa după Mircea Cărtărescu”, Revista 22, 919 [en línea] CIOBANU, Vitalie (2002): "Evadarea din "corp" sau al doilea Orbitor de Mircea

Cărtărescu, Contrafort, 6, 92. [http://www.contrafort.md/old/2002/92/353. html; 10/07/2019]

DIZ VILLANUEVA, Alba (2015a): "Ecos de la historia rumana en la literatura: las miradas de Mircea Eliade y Mircea Cărtărescu", Revista de filología románica, 32: $131-142$.

(2015b): "El erotismo en Cegador: infancia, ciudad, madre", Revista de filología románica, Anejo, VIII, 25-37.

IACOB, Mihai (2017a): "Din Levant la Madrid: formarea brandului Mircea Cărtărescu în Spania", (ed.). Călători și Călătorii. A privi, a descoperi. Bucarest: Editura Universității București.

(2017b): "De la tricoul cu mandală la cămașa cu mânecă scurtă sau negocierea imaginii scriitorului tradus: două lecturi publice ale lui Mircea Cărtărescu în Spania”, (ed.). Teritorii, Granițe, Comunități. Reconfigurări indentitare intr-o lume (dis)continuă. Bucarest: Editura Universității București.

LIPS, Marguerite (1926): Le style indirect libre. Paris: Payot.

MORA, Vicente Luis (2016): "Einstein y la literatura. La metáfora de la realidad y la relatividad de la metáfora", Revista de Occidente, 422: 119-133.

MUÑOZ CARROBLES, Diego (2011): "Poesía urbana rumana: Bucarest en la obra de Mircea Cărtărescu", Ángulo Recto: Revista de estudios sobre la ciudad como espacio plural, 3: 245-252.

POPESCU, Simona (2015): Autorul, un personaj. București: Editura Paralela 45.

POSADA, Adolfo R. (2018): "La recepción de Mircea Cărtărescu en España”, Quaestiones Romanicae VI: Lenguas y Literaturas Españolas, VI, 477-485.

POZUELO YVANCOS, José María (1993): Poética de la ficción. Madrid: Síntesis.

PUJANTE, Pedro (2019): Mircea Cărtărescu. La rescritura de lo fantástico. Editorial académica española.

RONEN, Ruth (1994): Possible worlds in literary theory. Cambridge: Cambridge University Press. 
RYAN, Marie-Laure (1985): "The Modal Structure of Narrative Universes", Poetics Today, 8, 3: 717-755.

SCHNEIDER, Ana-Karina (2016): "The Discourse of Self-Representation in Literary Studies in 1980s Romania", Journal of Narrative Theory, 46, 339-365.

TEGMARK, Max (1999): "The interpretation of Quantum Mechanics: many worlds or many words?”, (M. H. Rubin \& Y. H. Shih). Fortschritte der Physic, 46, 855-862.

VARGAS LLOSA, Mario (1978): La Orgía Perpetua. Barcelona: Bruguera.

\section{PERFIL ACADÉMICO Y PROFESIONAL}

Graduada en Lenguas, Literaturas y Culturas Románicas con Premio Extraordinario (2016) por la universidad de Salamanca, desarrolla su tesis doctoral sobre la teoría de la épica del siglo XVIII en el marco del proyecto 'Teoría de la lectura y hermenéutica literaria en la Ilustración (1750-1808): edición y estudio de fuentes' (FFI2016-80168-P). Actualmente es contratada predoctoral en el área de Teoría de la Literatura y Literatura Comparada de la universidad de Salamanca. Ha sido investigadora becada del Romanisches Seminar de la universidad de Heidelberg (2018).. Sus líneas de investigación engloban la literatura en lenguas románicas desde la perspectiva de la teoría literaria, cuyos resultados se han presentado en congresos internacionales (Trier, Heidelberg, Biblioteca Nacional de Rusia - San Petersburgo) y en revistas como Cuadernos de Estudios del siglo XVIII o Tropelías. Revista de Teoría de la Literatura y Literatura Comparada.

Fecha de recepción: 06/05/2019

Fecha de aceptación: 12/07/2019 